\title{
“VIVA A ITÁLIA E SEU GLORIOSO EXÉRCITO!” A IMIGRAÇÃO ITALIANA E AS MANIFESTAÇÕES DE ITALIANIDADE NAS MEMÓRIAS DE ANDREÁ POZZOBON (1885-1915)
}

DOI: http://dx.doi.org/10.15448/2178-3748.2015.1.19877

\author{
Maíra Ines Vendrame \\ Doutora em História (PUCRS) \\ Pós-doutoranda PNPD/CAPES-UFSM \\ vricamaira@yahoo.com.br
}

\begin{abstract}
RESUMO: O presente artigo parte da trajetória do imigrante Andrea Pozzobon para analisar questões como a experiência migratória e a acomodação nos núcleos de colonização. Nas comunidades fundadas do outro lado do Atlântico surgiu a preocupação com a renovação dos vínculos com a pátria de origem através da realização de festividades. Os acontecimentos envolvendo a Itália e a participação na Primeira Guerra, em 1915, repercutiram entre a população colonial, gerando manifestações de apoio, reforçando o sentimento de pertencimento, ocasionando, por outro lado, conflitos entre os imigrantes e padres. As manifestações de italianidade se apresentavam como um mecanismo para construir uma identidade, estabelecer certa diferenciação e proeminência, evidenciando a heterogeneidade do grupo imigrante e ideias conflitantes de pertencimento.
\end{abstract}

PALAVRAS-CHAVE: Imigração Italiana.Italianidade.Conflitos.

ABSTRACT This article presents the trajectory of the Italian immigrant Andrea Pozzobon to analyze issues such as migratory experience and accommodation in colonization centers. In communities founded on the other side of the Atlantic was a concern with the renewal of ties with the country of origin by conducting festivities. The events surrounding the Italy and it participation in World War I, in 1915, echoed between the colonial population, generating expressions of support, reinforcing the feeling of belonging, causing, on the other hand, conflicts between immigrants and priests. Expressions of Italian identity are presented as a mechanism to build an identity, establish some differentiation and prominence, showing the heterogeneity of the immigrant group and conflicting ideas of belonging

KEY WORDS: Italian Immigration.Italianism.Conflicts

\section{INTRODUÇÃO}

A obra Uma odisséia na América, publicada em 1997, é formada por manuscritos, crônicas, poesias, relatos de viagem e as memórias do imigrante italiano Andrea Pozzobon. Nela, encontramos assuntos como a preparação da transferência da família para o outro lado do Atlântico, o adeus a pátria, a travessia, a chegada à região colonial do sul do Brasil e as experiências vivenciadas no novo espaço. Somente mais recentemente a obra vem chamando a atenção entre os estudiosos, uma vez que foi apenas com a sua publicação que se tomou conhecimento da riqueza desse material. Organizado por Zolá Franco, neto de Andrea Pozzobon, o livro chama a atenção não apenas pelo protagonismo do italiano em relação à

Oficina do Historiador, Porto Alegre, EDIPUCRS, v. 8, n. 1, jan./jun. 2015, p. 21-41. 
imigração, mas também pelas opiniões e descrições dos acontecimentos locais de um dos primeiros testemunhos do deslocamento camponês europeu para o Rio Grande do Sul nas últimas décadas do século XIX. ${ }^{1}$ Diferentemente da maior parte dos conterrâneos que se estabeleceu nas regiões coloniais, o referido imigrante sabia ler e tinha grande domínio da escrita, conforme se pode perceber através das experiências, acontecimentos e opiniões que deixou registrado. ${ }^{2}$

Por meio dos escritos de Pozzobon é possível analisar de que modo se manifestou a questão do apego à pátria distante nas regiões coloniais, bem como a preocupação em renovar os vínculos de ligação com a península. As memórias do imigrante permitem chegar a detalhes do processo imigratório, apreender os sentimentos, desejos e intenções dos indivíduos que chegaram ao território sul-rio-grandense. O estudo de uma experiência singular possibilita compreender o universo sócio-cultural do qual o sujeito fazia parte. Para além das opiniões e escolhas tomadas por Andrea Pozzobon, através de seus escritos é possível analisar o surgimento de pequenas configurações sociais e culturais, demonstrando a estruturação das comunidades nas zonas de colonização italiana do Brasil meridional. A fundação de novas capelas, devoções e associações de mútuo-socorro definiram os contornos dos espaços nas áreas de ocupação.

Neste artigo, analisar-se-á, além da trajetória de Pozzobon, a vivência de conflitos entre os imigrantes promotores de atividades nacionalistas italianas e aqueles que se opunham a tais manifestações. Geralmente, nos núcleos coloniais, quem fazia oposição a organização de comemorações das datas nacionais e edificações de monumentos eram os padres romanizados sintonizados com as orientações da Igreja. Durantes as primeiras décadas do século XX, as divergências irão se intensificar devido às investidas imperialistas da Itália na África e a entrada na Primeira Guerra, em 1915. Nesse sentido, os eventos que estavam ocorrendo do outro lado do Atlântico repercutiam nas comunidades fundadas por imigrantes, ativando as rivalidades já existentes entre grupos locais. A trajetória de Andrea Pozzobon

\footnotetext{
${ }^{1}$ Outro escritor da imigração popular europeia para o sul do Brasil entre os séculos XIX e XX foi o imigrante Júlio Lorenzoni. Para uma análise da imigração italiana através da obra de Júlio Lorenzoni e a da trajetória de ambos os imigrantes, ver: FRANZINA, 2010; ZANINI, 2006.

${ }^{2}$ Escrita de si, memória, autobiografia e diário de viagens são termos que se referem à ação de certos sujeitos quando resolvem escrever sobre seu passado, retratar experiências e impressões do que viram, vivenciaram e sentiram. Na hora de colocar no papel tantos e tantos anos de vida, parece óbvio dizer que a subjetividade estará presente nas escolhas do que será registrado. A "escrita de si" se baseia na ideia de que a vida individual tem importância, que é digna de ser narrada como uma história que pode e deve sobreviver na memória dos outros: o autor "postula uma identidade para si" (GOMES, 2004, p. 12). Filtragem e ocultamento de fatos fazem parte do processo de seleção, assim como destaque a certos acontecimentos que o autor julga digno de ser lembrado. Para este artigo utilizou-se, além de GOMES (2004), os trabalhos de SEYFERTH (2005) e GOMES e SCHMIDT (2009) para as questões de narrativas autobiográficas.
}

Oficina do Historiador, Porto Alegre, EDIPUCRS, v. 8, n. 1, jan./jun. 2015, p. 21-41. 
surge, no presente trabalho, como um fio condutor da pesquisa, propiciando a abordagem de assuntos e questões importantes para se entender como se deu a integração dos imigrantes e a estruturação das comunidades nas regiões de colonização italiana.

\section{O IMIGRANTE ANDREA POZZOBON}

Em 1878 chegaram à Colônia Silveira Martins os primeiros grupos de imigrantes italianos, constituídos na maior parte por camponeses e pequenos proprietários originários da Província de Treviso. Esse foi o caso do amplo agregado de famílias que partiu da Itália sob a liderança do camponês Paolo Bortoluzzi, estabelecendo-se todos num dos núcleos da referida região colonial e fundando o povoado do Vale Vêneto. ${ }^{3}$ Posteriormente, em 1885, chegara o imigrante Andre Pozzobon, acompanhado dos pais, avô, irmãos e esposa. Esse grupo se fixou na comunidade de Arroio Grande, localizada a pouca distância do município de Santa Maria e próximo aos outros núcleos de colonização italiana. Também originário da Província de Treviso, Pozzobon havia nascido em maio de 1863, na aldeia de Carpenedo, município de Cavasagra.

Em suas memórias, Andrea narra em que circunstância recebeu o comunicado do patriarca da decisão de partirem todos do grupo familiar para o além-mar. No momento em que prestava serviço militar, recebeu uma carta do pai, notificando que a família estava se preparando para imigrar para a América. Fazia dois anos que o jovem servia no "Exército Real", mantendo-se durante esse período afastado da casa paterna. Demonstrando certo descontentamento com tal decisão, afirmou que como filho mais velho a carta "insinuava estar o destino dos Pozzobon em minhas mãos", estando todos a aguardar sua decisão. O jovem de 22 anos lamentava ter de abandonar a pátria, amigos, parentes e o amor que sentia por uma jovem conhecida, que durante algum tempo havia trabalhado na casa dos pais.

Porém, acatando a determinação paterna, apanhou "a pena humildemente e, contra a vontade", respondeu afirmando que imigraria com os familiares para a América. $\mathrm{Na}$ sequência, manifestou que a escolha pela transferência para além-mar tinha por objetivo "melhorar as condições econômicas da família, que passava privações". Como se encontrava afastado da casa dos genitores, tinha esquecido as dificuldades econômicas enfrentada pelos

\footnotetext{
${ }^{3}$ Sobre a trajetória do imigrante Paolo Bortoluzzi desde a comuna de Piavon, província de Treviso, até a região colonial do centro do estado do Rio Grande do Sul, ver: VENDRAME, 2013.
}

Oficina do Historiador, Porto Alegre, EDIPUCRS, v. 8, n. 1, jan./jun. 2015, p. 21-41. 
pais, segundo ele, pobres camponeses que viviam "a serviço de poderosos senhores, proprietários das terras férteis que se estendiam entre Castelfranco e Istrana" (POZZOBON, 1997, p. 34-37).

O peso da autoridade paterna e a abdicação das vontades individuais em nome do coletivo aparecem como fatores que influenciaram a tomada de decisão. Muito além de ser um projeto individual de homens com espírito aventureiro, a ideia da emigração era uma decisão conjunta, articulada em família ou no grupo parental extenso, podendo, em alguns casos, envolver quase toda uma aldeia. Isso tudo contribui para avaliarmos a questão da autonomia dos imigrantes em relação às escolhas de deslocamento, o desempenho ativo na articulação de estratégias que assegurassem determinados benefícios no local de destino e o respeito aos planos coletivos articulados em ambos os lados do Atlântico por indivíduos que se conheciam ou mantinham algum vínculo de parentesco.

As dificuldades econômicas vivenciadas pela família Pozzobon, somadas às reduzidas chances de alterar a condição de camponeses que trabalhavam em terras dos "poderosos senhores" como bracciante 4 ou arrendatários, certamente influenciaram na escolha do caminho da emigração. O afastamento dos jovens para prestar serviço militar era uma questão que prejudicava a economia doméstica, influenciando ao mesmo tempo na mudança de estratégias em relação à reprodução familiar. Logo, a imigração para a América surge como uma escolha para garantir a coesão do grupo e a manutenção de determinadas práticas socioculturais bastante antigas entre as famílias camponesas do norte da Itália. Especialmente entre os vênetos, lombardos e trentinos, a questão do recrutamento militar aparece como um dos fatores que impulsionaram o processo emigratório. A convocação para o Exército - de homens entre 19 (dezenove) a 30 (trinta) anos - causava prejuízos à economia das famílias camponesas, alterando as estratégias em relação à reprodução do grupo. Deste modo, em muitos casos, quando os filhos se encontravam no exército ou eram convocados para o serviço militar, os chefes de famílias viam no chamamento para as forças armadas um impulso para emigrar, solicitando, desse modo, a dispensa de tal obrigatoriedade (GROSSELLI, 1987, p. 99). A vontade de afastar o filho do exército talvez tenha sido uma das motivações que levou a família de Andrea a desejar abandonar definitivamente a Itália.

$\mathrm{Na}$ aldeia de origem, durante meses, os Pozzobon e outros que os acompanhavam esperaram pacientemente pelo recebimento dos documentos - autorizações das autoridades e das instruções para iniciar "a transferência para nossa colônia de Arroio Grande". Os

${ }^{4}$ Trabalhadores braçais que não possuíam a propriedade da terra.

Oficina do Historiador, Porto Alegre, EDIPUCRS, v. 8, n. 1, jan./jun. 2015, p. 21-41. 
passaportes tinham que ser obtidos junto ao poder público local, e as informações em relação ao embarque vinham do porto de Gênova. Quando a família optou por abandonar a terra natal foram tomadas decisões para reforçar os vínculos e obrigações com outros conhecidos do lugar. Em outubro de 1885, dias antes da partida, foi realizado o casamento de Andrea com uma jovem do vilarejo de Carpenedo, cujos pais também iriam imigrar para a América. ${ }^{5} \mathrm{~A}$ realização do matrimônio fazia parte da preparação para a viagem, bem como a comercialização de parte dos bens. Como outros conterrâneos que se preparavam para deixar a comuna, provavelmente compareceram no cartório mais próximo para realizar as transações de venda dos pequenos pedaços de terras ou fazer doação a algum parente que permaneceria na Itália. ${ }^{6}$

A logística do deslocamento começou meses antes, sobretudo a partir do momento que passaram a receber cartas de um parente que já se encontrava em terras brasileiras. Segundo Andrea, "o primo Annibale Mattiuzzi”, com quem o patriarca mantinha correspondência desde 1884, já se encontrava instalado no sul do Brasil, resultando daí a resolução da família Pozzobon de imigrar. Graças à troca de informações pretérita, partiram todos sabendo que as terras eram "férteis e planas", pois "arroz, trigo, milho e frutas já estavam sendo cultivados há anos por colonos, na maioria do Vêneto" (POZZOBON, 1997, p. 51-52).

Desse modo, a possibilidade de contar com notícias e recomendações antes da partida indicam a existência de uma rede eficaz de circulação de correspondências. Esse circuito ligava indivíduos que se encontravam em ambos os lados do Atlântico, exercendo forte influência na escolha da imigração e também na preferência por determinado local de destino. A troca de cartas permitia a obtenção de informações variadas, aparecendo como um recurso eficaz para garantir maior segurança para os camponeses que optavam por tal caminho. Entende-se que essa possibilidade fomentou o deslocamento, garantindo a formação de amplos agregados de famílias conhecidas que, partindo juntas ou em momentos diferentes, fundavam novas comunidades nas áreas destinadas à ocupação europeia no sul do Brasil. Foi decisiva para o aumento dos fluxos migratório a questão da troca de correspondências com os conterrâneos que já estavam em terras brasileiras. A busca por informação antes da partida era prática seguida pelos camponeses da região do Vêneto, norte da península itálica (VENDRAME, 2013).

\footnotetext{
5 A pesquisadora Maria Catarina Zanini (2006, p. 61-62) aborda alguns aspectos da trajetória do imigrante Andrea Pozzobon revelando detalhes da estrutura familiar italiana, sua organização patriarcal e os papéis de seus membros.

${ }^{6}$ Exemplos da realização de transações de vendas e outros contratos podem ser analisados no segundo capítulo do seguinte trabalho: VENDRAME, 2013.
}

Oficina do Historiador, Porto Alegre, EDIPUCRS, v. 8, n. 1, jan./jun. 2015, p. 21-41. 
As famílias se utilizaram das redes parentais e de amizade para transmitir notícias e prestar auxílio, permitindo que, de diferentes maneiras, os indivíduos encontrassem espaço na sociedade receptora. Possuir uma parentela solidária e coesa envolvida na imigração era um aspecto vantajoso para os contadini que partiram para "fazer a América". As possibilidades de obter vantagens nas terras distantes eram mais amplas ou mais reduzidas de acordo com a posição de cada um nas tramas parentais (VENDRAME, 2013). Na terra de origem, os auxílios se davam para além da questão da proximidade física entre as famílias, mas, sim, por existirem entre elas obrigações e cumplicidades reconhecidas. Isso também garantiu a formação de grupos de imigrantes de diferentes comunidades, muitas delas limítrofes, principalmente devido à presença de sólidos vínculos afetivos entre os indivíduos. ${ }^{7}$

\section{ENTRE OS CONTERRÂNEOS NO SUL DO BRASIL}

Ao chegarem a Porto Alegre, capital do Rio Grande do Sul, a família Pozzobon e os conterrâneos que a acompanhava pegaram o trem até Santa Maria. Fazia poucos meses que os serviços na linha férrea que conduzia à região central do estado haviam sido inaugurados. Depois de "10 horas de viagem, chegamos, ao anoitecer, à Estação Colônia [atual Camobi], término de nossa jornada", assim escreveu Andrea Pozzobon. Porém, o trem seguiria até a cidade de Santa Maria da Boca do Monte a poucos quilômetros de distância. Na pequena estação, o italiano Annibale Mattiuzzi aguardava a chegado dos parentes, organizando, na sequência, o deslocamento dos mesmos de carreta até o local de destino, percorrendo apenas cinco quilômetros (POZZOBON, 1997, p. 52-53). É provável que os recém-chegados tenham permanecido por algum tempo instalados na casa do parente Mattiuzzi, aguardando a obtenção de terras e a construção da nova residência. Desse modo, logo concretizaram a aspiração de se tornarem proprietários, anseio esse desejado pela maior parte dos imigrantes que chegavam aos núcleos coloniais do sul do Brasil.

Na pátria de origem, Andre Pozzobon havia frequentado a escola, atingindo, portanto, certo letramento que não era comum no universo camponês. Também "apreendeu a declinar latim, conjugar verbos e traduzir trechos litúrgicos e poéticos” (POZZOBON, 1997, p. 15). Assim que chegou à nova terra, o referido imigrante assumiu o cargo de professor primário. A

\footnotetext{
${ }^{7}$ Para saber mais sobre as articulações e iniciativas das famílias camponesas antes das transferências para o sul do Brasil, ver: VENDRAME, 2013.
}

Oficina do Historiador, Porto Alegre, EDIPUCRS, v. 8, n. 1, jan./jun. 2015, p. 21-41. 
opção por tal trabalho possibilitou que, posteriormente, em 1892, fosse nomeado oficialmente diretor da primeira escola italiana - subvencionada pelo consulado italiano da capital do Estado - aberta na comunidade de Arroio Grande. Para desempenhar a atividade de professor, passou a percorrer diariamente muitos quilômetros a cavalo até os diferentes locais ocupados por famílias imigrantes. Inicialmente apenas dava aulas em língua italiana, passando, na sequência, também a ensinar em língua portuguesa.

Foi como professor que Andrea tirou parte significativa do sustento da família, não deixando, porém, de realizar atividades ligadas à produção agrícola. Posteriormente, também passou a investir nas atividades comerciais. ${ }^{8}$ Ao se instalarem nos núcleos coloniais, as unidades familiares não ficavam dependentes de apenas um tipo de trabalho. Concomitantemente às atividades ligadas ao cultivo, dedicavam-se a outros trabalhos artesanais ou comerciais -, garantindo, desse modo, maior segurança na manutenção do equilíbrio doméstico.

Em janeiro de 1897, em contrato firmado com comissão da paróquia de São Marcos, além de lecionar diariamente para as crianças, Andrea assumiu a responsabilidade de ministrar o catecismo numa pequena capela, recebendo por cada aluno o valor de 500 réis mensais. Registrou em suas memórias alguns dos contratos assumidos, dando indicação de que a atividade de professor se tornou cada vez mais importante para ele e necessária para garantir o sucesso dos investimentos na nova terra. A existência de uma relação de nomes de 330 alunos - referentes há diversos anos - que frequentaram a escola em Arroio Grande, aponta para o interesse e preocupação das famílias italianas em relação à educação das crianças. Também indica a importância que as atividades desempenhadas por Andrea tiveram na região, garantindo que o imigrante alcançasse certo prestígio e respeito entre os conterrâneos (POZZOBON, 1997, p. 74-172-173).

Nos povoados coloniais do sul do Brasil, os italianos que possuíam algum tipo de conhecimento em relação à leitura e escrita passavam a se dedicar à atividade de professor e catequista nas comunidades recém-fundadas. Além disso, se envolviam diretamente na organização das atividades sócio-religiosas e, em alguns casos, na fundação de associações de assistência local. Em Arroio Grande, Andrea também passou a atuar como agente consular, aparecendo, ainda, como um dos fundadores da sociedade de mútuo-socorro "Luigi Amedeo

\footnotetext{
${ }^{8}$ No ano de 1915, constatou-se o funcionamento do estabelecimento comercial "André Pozzobon \& Filhos, Casa de Fazendas, Peças, Ferragens, Miudezas, Seccos e Molhados - Produtos Coloniais”, na Estação Colônia. Esta localidade ficava a poucos quilômetros da comunidade de Arroio Grande, onde inicialmente a família Pozzobon havia se estabelecido.
}

Oficina do Historiador, Porto Alegre, EDIPUCRS, v. 8, n. 1, jan./jun. 2015, p. 21-41. 
di Savoia - Duca Degli Abruzzi”, conforme veremos na sequência. Aos agentes, geralmente, cabia a responsabilidade de assistir as escolas subvencionadas pelo governo italiano, levar as demandas dos conterrâneos às autoridades consulares da capital, transmitir informações e orientar os italianos sobre diversas questões - como esclarecer a população colonial sobre as possibilidades de retorno para a terra natal e auxílios conferidos àqueles que tencionavam fazer a viagem de volta. Esse papel era também desempenhado pelo padre Antônio Sório na região colonial. ${ }^{9}$

A realização de festividades, homenagens e edificações que lembravam a ligação com a pátria de origem também era um assunto que, geralmente, contou com o envolvimento dos agentes consulares. Um exemplo disso se observará no desempenho de Andrea Pozzobon que - enquanto membro da capela de São Marcos - tornou-se um apoiador das iniciativas de promoção do sentimento de italianidade e assistência entre os italianos. A participação dos imigrantes em agregações religiosas e leigas permitia a criação de vínculos e a demarcação de diferenciações entre a população local. Tais cooperações foram de extrema importância no estabelecimento das bases associativas e a estruturação das comunidades, pois facilitaram a inserção das famílias imigrantes que continuavam a chegar à região colonial. Desse modo, os espaços sagrados e associativos permitiram a fundação de uma localidade, do surgimento do sentimento de pertencimento e da construção de uma identidade em terras brasileiras.

No povoado de Arroio Grande, além de participar da construção da igreja de São Marcos, Andrea, em 1896, foi um dos fundadores - juntamente com outros 21 sócios - da Sociedade Italiana de Mútuo-Socorro Luigi Amedeo di Savoia - "Duca Degli Abruzzi". ${ }^{10}$ Desta, Pozzobon tornou-se presidente, fazendo também parte da Sociedade de Mútuo-Socorro Humberto I, criada em 1885 na comunidade de Silveira Martins pelo amigo o padre Antônio Sório. A proximidade entre Pozzobon e Sório, de certa forma, possibilita compreender o apoio que o primeiro dava ao desempenho do pároco da sede da região colonial. Os vínculos de compadrio reforçaram as afinidades existentes entre ambos, pois, em 1899, os sobrinhos do padre Sório - Luiz Bianchi e Mariana Sório - aparecem apadrinhando uma das filhas de Andrea. A pia batismal servia para reforçar os laços e estabelecer parentesco espiritual entre as famílias e indivíduos que compartilhavam opiniões, participavam das associações locais e assumiam papéis semelhantes na política cotidiana (VENDRAME, 2013, p. 241). Também serviam para criar vínculos e afinidades entre os imigrantes que haviam partido de diferentes

\footnotetext{
${ }^{9}$ Sobre a atuação do padre Antônio Sório entre os italianos do sul do Brasil, ver: VENDRAME, 2013.

${ }^{10}$ Statuto "Della Societá Italiana Pátria e Soccorso Duca Degli Abrazzi” de São Marcos, 1896, p. 3. Centro de Pesquisas Genealógicas de Nova Palma (CPG-NP).
}

Oficina do Historiador, Porto Alegre, EDIPUCRS, v. 8, n. 1, jan./jun. 2015, p. 21-41. 
regiões da península itálica e, por vezes, não se encontravam na mesma condição social e nem tinham partilhado de semelhantes experiências migratórias.

Os imigrantes expressaram sua ligação com a pátria italiana, a família real e os heróis que haviam participado da Unificação, assumindo as sociedades de mútuo-socorro papel fundamental na constituição da identidade italiana no exterior. ${ }^{11}$ Isso não impedia que investissem na construção de igrejas e na busca por padres residentes na comunidade. Tanto o sentimento de italianidade como o de catolicidade eram aspectos que favoreceram a identificação de grupo entre os imigrantes. É através de símbolos e vínculos variados que o sentimento de pertencimento ia se constituindo, dando ensejos ao surgimento de grupos de oposições local.

Não podemos negar a presença de italianos com fortes ideais anticlericais - católicos liberais que viviam nos núcleos coloniais e faziam oposição às iniciativas dos padres de orientação romanizante. Um exemplo de desempenho de católico liberal pode ser percebido na conduta do imigrante Andrea, fazendo em suas memórias constantes críticas à postura dos sacerdotes, tanto na Itália como na localidade de adoção. Procurando reforçar a ligação com a pátria de origem, em 1885, foi fundada em Silveira Martins a primeira banda de música com o nome de José Garibaldi. Em homenagem a Garibaldi, símbolo e herói da Unificação Italiana, foi edificado um monumento na praça central da comunidade, onde foi colocado o busto do mesmo. Apesar da oposição do padre local à edificação, os imigrantes "garibaldinos" levaram a cabo tal empresa como forma de celebrar sua nacionalidade italiana. ${ }^{12}$

Portanto, nas comunidades coloniais, alguns imigrantes manifestavam seu sentimento de italianidade ao apoiarem iniciativas como a construção de monumentos e festejos. As sociedades de mútuo-socorro tiveram papel fundamental na promoção de atividades que permitissem a exteriorização da identidade italiana entre as famílias camponesas que ocuparam os núcleos coloniais. Nem todos os italianos eram apoiadores do modelo de igreja trazido pelos padres pertencentes às ordens religiosas sintonizadas com as orientações conservadoras do papado de Roma. Existiam imigrantes que preferiam sacerdotes que tivessem uma postura mais liberal - como era o caso do professor Andrea - e, consequentemente, fossem apoiadores das manifestações de nacionalidade - como as festividades e comemorações do dia 20 de setembro, marco da Unificação italiana. Não foram

\footnotetext{
11 Nas grandes cidades, os grupos de imigrantes, através das sociedades de mútuo-socorro, também tiveram papel fundamental no processo de construção da identidade italiana (HOSPITAL, 1999: CONSTANTINO, 2008).

${ }^{12}$ Para saber mais sobre as divergências entre imigrantes garibaldinos e os apoiadores das iniciativas dos padres na ex-Colônia Silveira Martins, ver: VÉSCIO, 2001; VENDRAME, 2007, 131-145.
}

Oficina do Historiador, Porto Alegre, EDIPUCRS, v. 8, n. 1, jan./jun. 2015, p. 21-41. 
apenas simples camponeses imigraram para o sul do Brasil, tendo alguns um nível de instrução bastante elevado em relação ao grupo social do qual fazia parte. Outros traziam experiências da participação nas guerras pela Unificação Italiana, apresentando-se nos núcleos coloniais como garibaldinos, defensores dos valores de patriotismo e da natureza leiga e liberal do Estado. Já alguns, como Andrea Pozzobon, tinham sido soldados no exército NACIONAL DA JOVEM PÁTRIA, MANIFESTANDO FORTE SENTIMENTO PATRIÓTICO NAS TERRAS DE ADOÇÃO.

\section{"VIVA A ITÁLIA E SEU GLORIOSO EXÉRCITO!"}

Como vimos no presente artigo, Andrea Pozzobon tornou-se agente consular na comunidade de Arroio Grande. Entre os imigrantes, o referido título era uma designação bastante almejada, conferia certa notoriedade e "possibilidade de ascensão social". Escolhidos entre os indivíduos com algum prestígio local, os agentes constituíam a trama essencial da rede consular, propiciando a ligação entre o consulado, responsável por um amplo território, e as famílias camponesas residentes nos afastados núcleos de colonização do Estado do Rio grande do Sul (Cacioli apud IOTTI, 2010, p. 93). Apesar de, muitas vezes, os agentes representarem uma das únicas vias para os italianos requererem auxílio do consulado, nem sempre os sujeitos que ocupavam tal posição possuíam preparação para assumir o cargo. Nem todos haviam recebido designação oficial para desempenhar tal papel, porém, se colocavam como agentes locais fazendo a mediação entre a população colonial e as autoridades consulares distantes.

Ao atuar como agente consular, o imigrante Andrea estava de certa forma atendendo as expectativas dos conterrâneos, já que possuía habilidades que não eram comuns no seu grupo social. Em algumas ocasiões, colocou-se como emissário dos imigrantes, denunciando os excessos cometidos pelos representantes da municipalidade de Santa Maria na administração pública da região colonial. Já em outros momentos, transmitia ao agente consular italiano Humberto Ancarani, residente naquela cidade, as reclamações dos conterrâneos, mantendo-o informado sobre as iniciativas tomadas pela direção da sociedade "Duca degli Abruzzi”. Esta também prestou "festiva homenagem", hasteando "bandeiras e flâmulas", quando da visita em Arroio Grande do cônsul Ancarani e da autoridade municipal de santa-mariense. O imigrante Andrea conferiu "boas-vindas aos visitantes", em nome de

Oficina do Historiador, Porto Alegre, EDIPUCRS, v. 8, n. 1, jan./jun. 2015, p. 21-41. 
toda a colônia, e, em troca, o agente consular prometeu "seu valioso apoio" às demandas dos italianos (POZZOBON, 1997, p. 200). Aqui, pode-se avaliar o desempenho do professor que se colocava como representante dos conterrâneos, favorecendo, ao mesmo tempo, os próprios projetos individuais, como o sucesso das atividades no campo comercial através da fundação de uma "Casa de Fazendas, Louças, Secos e Molhados".

Constatou-se que Andrea viajou duas vezes para a Itália, a primeira vez em 1904 e a segunda em 1911, no qual participou de exposições internacionais. Em ambas as ocasiões, escreveu suas impressões, manifestando certa adoração pela cultura italiana. ${ }^{13}$ Acredita-se que, em 1911, o imigrante foi tomado pelo entusiasmo nacionalista fruto da vitória na conquista da Líbia, retornando para o sul do Brasil com a ideia de erigir um monumento aos soldados que haviam morrido na guerra. Provavelmente, Andrea foi tomado pelos festejos do “Jubileu da Pátria", celebrado no referido ano. Assim, ao planejar a edificação do referido monumento, os italianos estariam demonstrando a existência do sentimento patriótico entre os conterrâneos, reforçando, de tal maneira, a ligação com a pátria distante.

Em suas memórias, Andrea Pozzobon afirma que, em outubro de 1912, a sociedade "Duca degli Abruzzi” promoveu a realização de subscrição para arrecadar recursos para construir um monumento em "memória aos heróis que, nos campos da Líbia, deram suas vidas pela grandeza da Itália". ${ }^{14}$ No entanto, expôs que obstáculos se impunham à concretização daquela manifestação que exaltaria o "sentimento pátrio", denunciando que as barreiras vinham tanto do subintendente, residente em Silveira Martins, quanto da autoridade diocesana. Diante da intenção de construir um monumento em frente da igreja, a "autoridade caipira do bispo de Santa Maria" se opôs "porque a lápide é profana". Assim, procurando vencer a oposição, Andrea cedeu um retângulo de terra junto à praça, suficiente para ser erguido o monumento, deixando com isso os "repulsivos corvos [padres e bispo] grasnarem à vontade" (POZZOBON, 1997, p. 200-201).

Através da mobilização promovida pela sociedade de mútuo-socorro, pode-se perceber de que modo os vínculos com a pátria de origem eram renovados nos núcleos coloniais. Foi importante para isso o papel de algumas lideranças e organizações locais. A ereção de monumentos, fundação de associações e a promoção de festejos eram eventos que procuravam reforçar os laços dos imigrantes com a Itália, fazendo lembrar a todos -

\footnotetext{
${ }^{13}$ Os cadernos de anotações de Andrea Pozzobon se encontram na caixa da família Pozzobon no Centro de pesquisas Genealógicas de Nova Palma.

${ }^{14}$ Depois da derrota na Etiópia, em 1896, os italianos haviam interrompido por quinze anos a política de expansão imperialista no território africano. Porém, em 1911, às vésperas da $1^{\text {a }}$ Guerra Mundial, empreenderam uma nova tentativa colonialista, obtendo, nesse momento, sucesso com a conquista da Líbia.
}

Oficina do Historiador, Porto Alegre, EDIPUCRS, v. 8, n. 1, jan./jun. 2015, p. 21-41. 
população local e externa - dessa ligação e dos sentimentos mantidos com a pátria distante. Internamente às comunidades, as manifestações de italianidade também se apresentavam como um mecanismo para estabelecer certa diferenciação e proeminência. A participação dos representantes das sociedades de mútuo-socorro em solenidades promovidas na agência consular, localizada na cidade de Santa Maria, apresentava-se como uma oportunidade para as organizações coloniais demonstrarem sua importância, confraternizando com as autoridades municipais.

Voltando à questão da oposição à edificação do monumento aos italianos mortos na guerra da Líbia, Andrea dá indicação do surgimento de desacordo entre os membros da sociedade "Duca degli Abruzzi" que estavam cuidando da construção. Em carta aos sócios, anunciou sua decisão de se "retirar da associação e não mais assinar escritura de concessão do terreno para construção da pirâmide”, declarando, na sequência, que iria sair da comunidade de São Marcos. ${ }^{15}$ Apesar dessa manifestação, no mês seguinte, o referido imigrante escreveu ao cônsul italiano Humberto Ancarani ressaltando o quanto eram excessivas as despesas envolvendo a festa de inauguração do monumento aos heróis mortos na Líbia. Devido aos altos gastos, alertava que a sociedade "ver-se-á na triste contingência de não poder assistir um só sequer de seus sócios que venham a adoecer". Logo, fazia esta observação a fim de evitar o fim da associação Duca degli Abruzzi, o que "seria um prejuízo para a comunidade e para a colônia italiana". ${ }^{16}$

Apesar dos contratempos em relação à construção do monumento, em julho de 1913, foi inaugurada "a coluna monumental aos gloriosos mártires tombados na Líbia". Na solenidade, se apresentaram a banda musical José Garibaldi e Lyra Popular e os membros representantes das sociedades de mútuo-socorro presentes na região colonial. Presenciaram a “solene demonstração patriótica o Sr. Agente Consular de Santa Maria, o 'Cavalheiro' Ancarani, o intendente (...), os coletores estadual e federal, representantes do Exército e do periódico da Loja Maçônica Paz e Trabalho". A comemoração "não poderia ser mais brilhante e vibrátil", tendo concorrido "multidões de pessoas" de todas as partes. Depois das homenagens, "foi servido um suculento banquete, a mais de duzentas pessoas", e alguns italianos, em discurso improvisado, continuaram a enaltecer o "nosso glorioso exército e o monumento". Na opinião de Andrea (POZZOBON, 1997, p. 205), a cerimônia marcou a

\footnotetext{
${ }^{15}$ Carta de Andrea Pozzobon, de 18 de junho de 1913. In: POZZOBON, 1997, p. 202.

${ }^{16}$ Carta de Andrea Pozzobon ao Agente Consular da Itália Humberto Ancarani, 04 de julho de 1913. In: POZZOBON, 1997, p. 2-3-204.
}

Oficina do Historiador, Porto Alegre, EDIPUCRS, v. 8, n. 1, jan./jun. 2015, p. 21-41. 
“memória da população de São Marcos, que recordará sempre este evento, como o rei de todos os festejos".

Quando da inauguração da edificação, o professor - como representante da sociedade "Duca degli Abruzzi"17 - enalteceu "a gentil raça latina, da qual a Itália é mãe", como portadora de civilização e progresso. Sendo a pátria inimiga do barbarismo, viu-se, portanto, obrigada a "desencadear a guerra na Líbia contra a ferocidade muçulmana". Exalta os "Gloriosos combatentes" que lutaram pelo "enaltecimento da bandeira tricolor", derramando sangue em honra a pátria: "Viva a Itália e seu glorioso Exército! Viva o Rei! Viva o Brasil!"18 Imigrante Andrea Pozzobon enalteceu as atitudes dos compatriotas mortos, pronunciando vivas tanto para a Itália como para o Brasil. Como sujeito que imigrou obedecendo à ordem paterna, lamentou não ter podido lutar pelo "enaltecimento da bandeira tricolor", dando provas do sentimento nacionalista alimentado por ele nas terras de adoção.

Opinando sobre a realização de convite a um padre para benzer o monumento, afirmou em carta que para ele "isso não representava nem frio nem calor". ${ }^{19}$ Enquanto católico liberal não conferia importância à benção da edificação aos heróis da Líbia, certamente por acreditar que o valor e legitimidade da obra não dependiam da realização do ritual religioso. Ressaltase, então, a importância de analisarmos o conteúdo do discurso presente nos registros documentais, mas, especialmente, a posição do indivíduo que o pronuncia e suas pretensões enquanto ator social. Pozzobon desejava que aquela festividade nacionalista ficasse marcada na memória da população colonial, tornando-se um dos símbolos de identificação do grupo e ligação com a pátria de origem.

A edificação de monumentos como sinais das manifestações de nacionalismo italiano no exterior estão ligadas à investida imperialista no território africano, expressada na conquista da Líbia, e à existência de um forte sentimento patriótico ligado às comemorações do jubileu da Unificação Italiana, em 1911. A vitória do exército na guerra ítalo-turca reacendeu o sentimento patriótico entre os imigrantes que se encontravam nos núcleos coloniais do sul do Brasil. O dia 27 de julho 1913 - data da inauguração da edificação - foi escolhido para rememorar e festejar o triunfo na guerra, sendo que, nos anos seguintes àquela comemoração aos "Heróis da Líbia", a população passou a assistir a solenidades de “demonstrações patrióticas", rememorando com música e banquete o acontecimento.

\footnotetext{
${ }^{17}$ A sociedade "Duca delgi Abruzzi" paga parte dos custos de edificação do monumento, enquanto a outra parte vem das contribuições conferidas por cento e cinco pessoas da região colonial (POZZOBON, 1997, p. $205,207$.

${ }^{18}$ Discurso proferido na inauguração do monumento aos heróis da Líbia. In: POZZOBON, 1997, p. 206.

${ }^{19}$ Carta de Andrea Pozzobon, 22 de julho de 1913. In: POZZOBON, 1997, p. 205.
}

Oficina do Historiador, Porto Alegre, EDIPUCRS, v. 8, n. 1, jan./jun. 2015, p. 21-41. 
Posteriormente a ereção, o monumento recebeu um o busto do rei italiano Humberto I e, também, uma placa com os seguintes dizeres: "Ai probi che sui campi libici diedero la vita per la grandezza dela pátria, la colonia, auspice, la societá Duca degli Abruzzi posero" (POZZOBON, 1997, p. 307). Desse modo, a sociedade de mútuo-socorro deixava registrada sua homenageavam aos gloriosos soldados que, para garantir a grandeza da Itália, haviam dado a vida.

Fig.1 - Festa de inauguração do monumento aos heróis da Líbia, em 27 de julho de 2013.

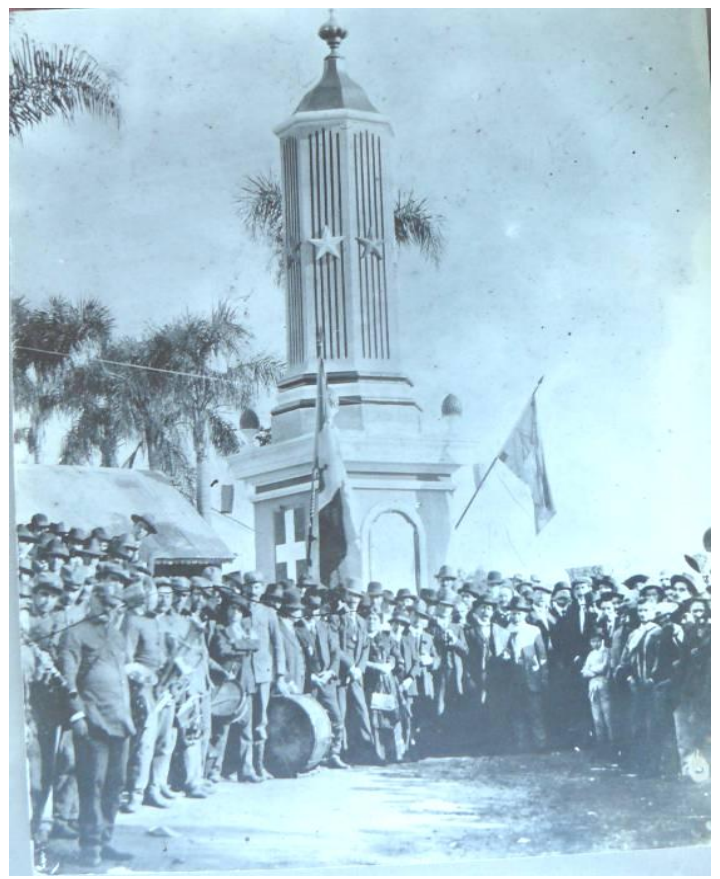

FONTE: Cantina Pozzobon, Arroio Grande.

Edificações de símbolos que lembravam a Itália unida e festividades passaram a ser realizadas como iniciativa para reforçar a ligação e apoio à pátria de origem. Na mesma época, em Silveira Martins, sede da ex-Colônia, foi construído na praça central da comunidade um monumento para homenagear Giuseppe Garibaldi. Em 1915, quando da entrada da Itália na Primeira Guerra, foi concluído com a colocação do busto ao herói italiano, Giuseppe Garibaldi (SCHWINN, 19--). Enquanto símbolo da Unificação italiana, Garibaldi era lembrado e reverenciado por meio da edificação de monumentos e quando grupos musicais e associações locais levavam seu nome.

Muitas das atividades organizadas pelos imigrantes ganhavam um caráter nacionalista, a exemplo da edificação que lembrava os soldados que haviam lutado na guerra de conquista da Líbia. Na praça da matriz de Silveira Martins, em 1910, era inaugurada uma coluna em homenagem a Giuseppe Garibaldi. Para a festividade, foi colocada uma foto do mesmo, sendo

Oficina do Historiador, Porto Alegre, EDIPUCRS, v. 8, n. 1, jan./jun. 2015, p. 21-41. 
apenas em 1914 fixado o busto de Garibaldi. A construção do monumento do herói da Unificação Italiana tinha por objetivo definir um dos símbolos da identificação dos imigrantes italianos no exterior, reforçando, assim, o sentimento de italianidade nas primeiras décadas do século XX. O envolvimento de lideranças locais na fundação de associações, na construção de monumentos e promoção de festividades, evidenciando, por vezes, uma forma de nacionalismo militar-patriótico, exemplifica os mecanismos acionados para definir a identidade italiana nos núcleos coloniais do Brasil meridional. Se por um lado, algumas edificações e atividades reforçavam a ligação com a terra de origem, entende-se que nem todas as famílias italianas estavam envolvidas ou preocupadas com tais acontecimentos.

As manifestações patrióticas, como indicadores da exaltação da italianidade, receberam oposição por parte de alguns padres nos povoados coloniais que as viam como afronta ao poder da Igreja Católica na região. No povoado de Silveira Martins, surgiram disputas entre o pároco e os italianos garibaldinos - que podiam ser nacionalistas, liberais ou maçons - tendo esses últimos pendurado "bandeiras injuriosas" perante a casa paroquial. Antes disso, o busto de Garibaldi havia aparecido pintado de alcatrão, dando início a uma troca de acusações e perseguições entre parte da população. Em comitiva, um grupo garibaldinos foi procurar indícios que provassem a culpabilidade do padre Frederico Schwinn entre os imigrantes que trabalhavam nas obras de reforça da Igreja Matriz (SCHWINN, 19--, p. 18). Tais disputas ocorreram devido às diferenças ideológicas, expressando-se, principalmente, na oposição à realização de comemorações de datas oficiais italianas. De um lado se encontravam os apoiadores dos padres, contrários à realização das festividades, do outro, estavam os imigrantes de orientação liberal, que nos povoados foram os promotores das homenagens aos heróis italianos.

O discurso intransigente de alguns sacerdotes ultramontanos motivou o surgimento de sérios conflitos, desencadeando o afastamento de alguns padres das comunidades. ${ }^{20}$ No ano de 1906, em Silveira Martins, o padre Mathias Schoenauer teve de se afastar devido oposição da maçonaria e a desavença com o italiano Antonio Fantoni, que disparou um tiro contra o padre que fugiu a noite do lugar (SCHWINN, 19--). A nacionalidade alemã dos missionários palotinos também apareceu como um dos motivos de críticas ao desempenho dos mesmos por parte da população colonial.

${ }^{20}$ Exemplos de conflitos ocorridos nos núcleos coloniais entre os padres e os imigrantes de orientação liberal foram apresentados nos seguintes estudos: VÉSCIO, 2001, POSSAMAI, 2005, VENDRAME, 2007.

Oficina do Historiador, Porto Alegre, EDIPUCRS, v. 8, n. 1, jan./jun. 2015, p. 21-41. 
Em 1915, com a entrada da Itália na Primeira Guerra, acirraram-se as oposições já existentes nos núcleos coloniais, especialmente, entre os imigrantes italianos que haviam emigrado de locais que pertenciam ao domínio austríaco. Logo, a declaração de guerra a Áustria gerou "grande ansiedade" entre a população. De acordo com Andrea Pozzobon (1997, p. 207-208), a sociedade de mútuo-socorro de Arroio Grande passou a angariar recursos financeiros para serem encaminhados aos "órfãos e mutilados" que haviam participado dos conflitos. Frente a tal iniciativa, surgiram críticas, principalmente entre aqueles que se opunham à participação da pátria no conflito mundial. Como elemento agravante, os filhos de imigrantes passaram a ser solicitados para se alistarem no Exército italiano, o que trouxe grande descontentamento por parte dos colonos que estavam em território brasileiro. Apesar disso, entre julho e setembro de 1915, um total de 392 jovens - imigrantes e descendentes foram para a Itália como soldados para participar da Grande Guerra. Desses, quatorze morreram nos campos de batalhas, sendo um de nome Alfredo Londero - 22 anos, solteiro filho de um dos principais comerciantes da Colônia Silveira Martins. ${ }^{21}$

As notícias das investidas colonialistas da Itália - como a conquista da Líbia - e a participação na Guerra incentivaram a realização de manifestações nacionalistas nas regiões coloniais do sul do Brasil entre 1915 e 1918. Durante esse período, surgiram atritos entre os imigrantes ligados à Itália - aqueles que haviam partido com passaporte italiano - e os que tinham saído de regiões pertencentes aos domínios austríacos - como os trentinos. Relatando sobre as oposições existentes nas colônias da Serra Gaúcha, o italiano Júlio Lorenzoni (1975, p. 170-172) afirmou que alguns tiroleses - das regiões do Tirol e Trento, áreas dominadas pela Áustria quando do momento da grande imigração - sempre mantiveram aversão ao elemento italiano, continuando a inimizade durante a Grande Guerra através de “manifestações verdadeiramente hostis". As provocações, muitas vezes, ocorriam não somente por meio da realização de festejos, mas também através da colocação na fachada das casas da bandeira austríaca. Diversos foram os casos de enfrentamento entre italianos e trentinos em Caxias do Sul durante o período dos conflitos no território europeu. ${ }^{22}$

Em Silveira Martins, o pároco Frederico Schwinn (19--, p. 28-32), que não era de nacionalidade italiana, passou a sofrer oposição por partes de alguns imigrantes que não

\footnotetext{
${ }^{21}$ Informações extraídas do livro comemorativo do Cinquentenário da imigração italiana no Rio Grande do Sul. In: Cinquantennio della colonizzazione italiana nel Rio Grande del Sul, 2000, p. 420-426. O comerciante Antônio Londero possuía casa de negócio em Silveira Martins.

${ }^{22}$ Sobre esses episódios de conflitos, ver: AZEVEDO, 1975, p. 218; POSSAMAI, 2005, p. 214-223.
}

Oficina do Historiador, Porto Alegre, EDIPUCRS, v. 8, n. 1, jan./jun. 2015, p. 21-41. 
concordavam com a construção de uma torre na igreja, em $1914 .{ }^{23}$ Segundo o referido sacerdote, contratempos atrasaram a conclusão da obra, principalmente por causa da guerra europeia que tornava tudo motivo de críticas. Em 1918, quando da inauguração da torre, alguns italianos caluniaram a obra e seus construtores, dizendo que a mesma "fora construída para servir de espionagem alemã" (SCHWINN, 19--, p. 6-7). Nos seus manuscritos, o padre Schwinn sinalizou para essa questão do surgimento de oposições por parte de paroquianos devido a Grande Guerra.

Já o imigrante Andrea Pozzobon, em suas memórias, não assinala a ocorrência de divergências locais durante o período da guerra e nem fornece qualquer outra informação sobre as repercussões locais do conflito que ocorria do outro lado do Atlântico. No entanto, anos antes da convocação aos imigrantes para servir à pátria italiana, Pozzobon (1997, p. 186) descreveu as manifestações contrárias por parte colonos que se opunham ao alistamento obrigatório determinado pelas autoridades brasileiras, em 1908. A obrigatoriedade do serviço militar provocou "um tumulto diabólico" na comunidade de Arroio Grande. Muitos colonos não queriam se inscrever porque eram italianos, e outros por serem filhos de italianos. Os inspetores dos bairros exigiram submissão da população colonial, porém, "o povo os vaiava". Por causa disso, veio de Santa Maria o agente consular que pediu aos imigrantes para "manterem-se fiéis à pátria e a respeitar as leis brasileiras". Apesar disso, no entardecer do mesmo dia, numa "vendinha" (bar) da mesma localidade, o inspetor Mattiuzzi foi "alvo de demonstrações hostis. E, aos gritos de "Viva a Itália, foram lançados ao ar inúmeros foguetes", exaltando a pátria de origem.

Os imigrantes procuravam evitar o cumprimento de determinadas leis brasileiras, e a convocação militar obrigatória causava revoltas organizadas por parte das famílias camponesas presentes nos núcleos coloniais. Um exemplo disso pode ser conferido no "motim" ocorrido em Silveira Martins, em 1903, quando mais ou menos cem colonos "armados de facão, pistola e alguns de armas de caça" se dirigiram para o centro de Silveira Martins, onde funcionava a subdelegacia de polícia e a Junta de Alistamento. Nesse momento, passaram a exigir de Claro de Oliveira (subintendente municipal) que seus nomes fossem retirados da lista de convocação para o serviço militar. Num "alarido infernal gritaram 'abaixo as firmas', 'rompa-se os livros de alistamento militar' e [que] isso fariam quer quisessem ou não as autoridades". Os imigrantes retornaram para suas casas após terem arrancado o edital

\footnotetext{
${ }^{23}$ O padre Frederico Schwinn permaneceu na administração religiosa da paróquia de Silveira Martins entre 1906 e 1918, período esse em que, provavelmente, deve ter escrito os seus manuscritos.
}

Oficina do Historiador, Porto Alegre, EDIPUCRS, v. 8, n. 1, jan./jun. 2015, p. 21-41. 
dos alistados que se encontrava afixado na porta da Igreja da paróquia. Uma investigação policial foi aberta para investigar os responsáveis por articular os protestos e as desordens, sendo inquiridos trinta indivíduos, porém, apenas onze foram investigados como chefes da mobilização criminosa que afrontou as leis do país. ${ }^{24}$

Por meio dos protestos contra a convocação militar, os "rebeldes", todos eles chefes de família - casados entre os vinte e trinta anos de idade - agiram para garantir a manutenção da condição de camponeses e a reprodução da unidade doméstica. $\mathrm{O}$ afastamento de um membro da casa, fosse ele o pai ou os filhos, desarticulava a economia camponesa, adiando projetos coletivos, causando danos à sobrevivência do grupo. Entende-se que as manifestações de revolta contra o alistamento se encontravam relacionadas aos prejuízos que o afastamento temporário de um indivíduo acarretava à família. Quando convocados para se alistarem, os imigrantes protestaram, advertindo sobre sua condição camponesa e também alardeando sua origem italiana sob os gritos de "Viva a Itália". Apresentar-se como soldado para servir a pátria mãe ou o país de adoção era uma escolha que causava prejuízos às economias domésticas camponesas, podendo acarretar consequências irreversíveis para a reprodução familiar. A unidade doméstica funcionava como uma pequena empresa que dependia do trabalho coletivo de todos os integrantes do grupo.

\section{CONSIDERAÇÕES FINAIS}

Neste artigo, analisou-se o envolvimento de alguns imigrantes na questão da preservação dos vínculos como a pátria de origem, participando de ambientes associativos que agregassem os chefes de famílias italianas. A integração entre a população colonial foi ocorrendo não apenas através dos laços já existentes entre grupos aparentados, mas também por meio da fundação de novos espaços onde eram constituídas, ampliadas e reforçadas as alianças, amizades e proteções. Redes de sociabilidades foram criadas a partir do desempenho de alguns indivíduos, aqui no caso os italianos idealizadores da criação de sociedades de mútuo-socorro a exemplo do imigrante Andrea Pozzobon. Logo, os encontros e cerimoniais permitiram a afirmação da existência da comunidade, de um espaço de direito e deveres, e da expressão de uma cultura.

\footnotetext{
${ }^{24}$ Processo-crime, Santa Maria, Maço 43, n 1296, Ano 1904, Arquivo Público do Estado do Rio Grande do Sul.
}

Oficina do Historiador, Porto Alegre, EDIPUCRS, v. 8, n. 1, jan./jun. 2015, p. 21-41. 
Ignorar as escolhas tomadas pelas lideranças locais de fundar associações, edificar monumentos e celebrar eventos é descuidar de uma das dimensões mais significativas do processo de constituição de um lugar e de uma identidade: o modo como os atores sociais pensavam e agiam no mundo no qual se encontravam inseridos. Além disso, como vimos no presente trabalho, a identificação de frentes de oposição na região colonial demonstra que os imigrantes não podem ser entendidos como um grupo homogêneo, pois havia diferenças entre eles que se manifestavam em posições políticas locais bem definidas. O comportamento de Pozzobon, de certa forma, indica para essa heterogeneidade de ideias e desempenhos existentes nos núcleos coloniais. Tais diferenças podem ser apreendidas na presença de opiniões críticas à postura dos padres sintonizados com as orientações conservadoras do papado, na conduta liberal e nacionalista de alguns italianos. Enquanto habitavam a Península, muitos não se consideravam italianos, antes trentinos, vênetos, lombardos, etc. Ao chegaram ao sul do Brasil, passaram a partilhar muito mais do que uma identidade regional, construindo a ideia de pertencimento a pátria italiana.

A presença desse sentimento de italianidade pode ser percebida em 1915, no número de imigrantes e filhos de imigrantes que serviram como soldados e voluntários na Grande Guerra. Do Rio Grande do Sul foram para a Itália 392 indivíduos para lutar na guerra. Levando em conta as manifestações de oposição dos italianos contra o alistamento militar aqui no Brasil, tendo em vista que tal serviço prejudicaria a reprodução do grupo e causava desequilíbrios à economia doméstica, considera-se significativa o número de indivíduos que abandonaram temporariamente o território sul-rio-grandense para lutar na Europa. Em 1915, o progresso econômico de determinadas regiões coloniais já era visível, propiciando que muitos filhos de imigrantes desejassem participar da Guerra. Além disso, nesse momento, a ideia de pertencimento à pátria italiana era um fator de identificação da população que se encontravam nas regiões de colonização do sul do Brasil.

Viu-se, também, que a acomodação dos imigrantes e a estruturação das comunidades não ocorreram de forma tranquila. As atividades realizadas nos núcleos coloniais demonstram que esse processo não se caracteriza como coerente e linear, bem como os imigrantes não podem ser entendidos como um grupo homogêneo que desde sempre partilharam de sentimentos comuns de identificação - como o de catolicidade. Dependendo do momento, os elementos que propiciavam a construção de uma identidade italiana em terras brasileiras variaram. Durante a Segunda Guerra Mundial, o monumento aos heróis da Líbia foi derrubado por ordem do governo brasileiro. Em 1996, um novo monumento foi construído,

Oficina do Historiador, Porto Alegre, EDIPUCRS, v. 8, n. 1, jan./jun. 2015, p. 21-41. 
porém, nessa nova edificação não encontramos referências à proposta inicial: a homenagem aos soldados que haviam combatido na guerra de conquista contra a Líbia. Somente aparece, numa das placas afixadas, os nomes dos 41 imigrantes pertencentes à associação de mútuosocorro "Duca Delgi Abruzzi" - fundada em 1896, na comunidade de São Marcos. Na nova construção, o monumento foi ressignificado, passanda a exaltar algumas qualidades dos imigrantes italianos que colonizaram a região colonial.

Em 24 de maio de 1998, a Associação Italiana de Santa Maria colocou uma placa com a seguinte frase: "Eles trouxeram no coração a vontade e a persistência; na alma, a coragem e a fé; no sangue, a fibra da raça; nas mãos, a força e o trabalho e colonizaram esta região". Desse modo, ressaltaram a coragem, o trabalho e a fé como símbolos da identidade dos imigrantes, atribuindo novo significado para o monumento construído na frente da igreja de São Marcos. Procurando reforçar o trabalho como uma das principais contribuições do grupo, no monumento foi fixada uma imagem com "rudimentar engenho de fabricar tábuas", erigido pelos italianos que povoaram o local. Assim, enquanto construção cultural, a definição dos elementos que promovem a constituição da identidade étnica relaciona-se às demandas de determinado momento, estando em constante elaboração, não sendo, portanto, imutável.

\section{REFERÊNCIAS:}

AZEVEDO, Thales de. 1975. Italianos e gaúchos: os anos pioneiros da colonização italiana no Rio Grande do Sul. Porto Alegre: A Nação - Instituto Estadual do livro.

BONFADA, Genésio. 1991. Os palotinos no Rio Grande do Sul. Porto Alegre: Pallotti.

Cinquantennio della colonizzazione italiana nel Rio Grande del Sul: 1875-192. 2000. $2^{\circ}$ Edição, Porto Alegre: Posenato Arte \& Cultura.

CONSTANTINO, Núncia Santoro de. 2008. O italiano da esquina: imigrantes meridionais na sociedade porto-alegrense. $2^{\mathrm{a}}$. Ed. Porto Alegre: EST edições

FRANZINA, Emílio. 2010. "A imigração italiana no Rio Grande do Sul nas memórias de Júlio Lorenzoni (1877-1928)". In: TEDESCO, João Carlos; ZANINI, Maria Catarina C. (orgs.) Migrantes ao sul do Brasil. Santa Maria: Ed. da UFSM, p. 63-84.

GOMES, Ângela de Castro (org.). 2004. Escrita de si, escrita da história. Rio de Janeiro: Editora da FGV.

GOMES, Ângela de Castro; SCHMIDT, Benito Bisso (orgs.). 2009. Memórias e narrativas autobiográficas. Rio de Janeiro; Porto Alegre: Editora FGV; Editora da UFRGS.

GROSSELLI, Renzo Maria. 1987. Vencer ou morrer: camponeses trentinos (vênetos e lombardos) nas florestas brasileiras. Florianópolis: Editora da UFSC.

HOSPITAL, Maria Silvia. 1999. "Construção da identidade e associações italianas: La Plata e Porto Alegre (1880-1920)". In: Estudos Ibero-americanos. PUCRS, v. XXV, n. 2, dezembro, p. 131-145.

IOTTI, Luiza Horn. 2010. Imigração e poder: a palavra oficial sobre os imigrantes italianos no Rio Grande do Sul (1875-1914). Caxias do Sul: EDUCS.

Oficina do Historiador, Porto Alegre, EDIPUCRS, v. 8, n. 1, jan./jun. 2015, p. 21-41. 
LORENZONI, Júlio. 1975. Memórias de um imigrante italiano. Porto Alegre: Sulina.

POSSAMAI, Paulo. 2005. "Dall'Italia siamo partiti": a questão da identidade entre os imigrantes italianos e seus descendentes no Rio Grande do Sul (1875-1945). Passo Fundo: Editora da UPF.

POZZOBON, Zolá Franco. 1997. Uma odisséia na América. Caxias do Sul: EDUCS.

SCHWINN, Frederico. 19--. Freguesia Silveira Martins. Caixa 5, Missão Brasileira. Arquivo Histórico Nossa Senhora Consquistadora, Santa Maria.

SEYFERTH, Giralda. 2005. "Cartas e narrativas biográficas no estudo da imigração". In: DEMARTINI, Zeila de Brito Fabri; TRUZZI, Oswaldo (orgs.). Estudos Migratórios: perspectivas metodológicas. São Carlos: EdUFSCar, p. 13-51.

VENDRAME, Maíra Ines. 2007. "Lá éramos servos, aqui somos senhores”: a organização dos imigrantes italianos na ex-colônia Silveira Martins (1877-1914). Santa Maria: Ed. da UFSM.

2013. Ares de vingança: redes sociais, honra familiar e práticas de justiça entre os imigrantes italianos no sul do Brasil (1878-1910). Tese (doutorado em história) Faculdade de Filosofia e Ciências Humanas, Pontifícia Universidade Católica do Rio Grande do Sul, PUCRS, Porto Alegre.

VÉSCIO, Luiz Eugênio. 2001. O crime do Padre Sório: Maçonaria e Igreja Católica no Rio Grande do Sul 1893-1928. Santa Maria: Ed. UFSM; Porto Alegre: Ed. da Universidade/UFRGS.

ZANINI, Maria Catarina Chitolina. 2006. Italianidade no Brasil meridional: a construção da identidade étnica na região de Santa Maria - RS. Santa Maria: Ed. da UFSM.

ARTIGO ENVIADO EM: 04/02/2015

ACEITO PARA PUBLICAÇÃO EM: 15/06/2015

Oficina do Historiador, Porto Alegre, EDIPUCRS, v. 8, n. 1, jan./jun. 2015, p. 21-41. 